\title{
Comunicação Organizacional na perspectiva da complexidade
}

\author{
Organizational Communication from \\ the complexity perspective
}

\author{
Comunicación Organizacional en \\ la perspectiva de la complejidad
}

\section{Rudimar Baldissera}

- Doutor em Comunicação pela Pontifícia Universidade Católica do Rio Grande do Sul (PUC-RS)

- Mestre em Comunicação/Semiótica pela Universidade do Vale do Rio dos Sinos (Unisinos)

- Especialista em Gerenciamento de Recursos Humanos pela Unisinos

- Graduado em Relações Públicas pela Universidade de Caxias do Sul (UCS)

- Professor do Curso de Comunicação da Faculdade de Biblioteconomia da Universidade Federal do Rio Grande do Sul (UFRGS)

- Professor do Programa de Pós-Graduação em Comunicação e Informação da UFRGS

- Autor do livro Comunicação organizacional: o treinamento de recursos humanos como rito de passagem e de artigos e capítulos de livros

- Atuação como consultor na área de comunicação, cultura e imagem organizacional

- rudimar.baldissera@ufrgs.br; rudimarbaldissera@bol.com.br. 
A Comunicação Organizacional é entendida, a partir do paradigma da complexidade, como processo de construção e disputa de sentidos no âmbito das relações organizacionais. Afirma-se que ela contempla três dimensões tensionadas e interdependentes: a organização comunicada (fala autorizada); a organização comunicante (fala autorizada e demais processos comunicacionais que se atualizam sempre que alguém estabelecer relação direta com a organização); e a organização "falada" (processos de comunicação que, não sendo a partir de relações diretas com a organização, referem-se a ela).

PALAVRAS-CHAVE: COMUNICAÇÃO ORGANIZACIONAL • PARADIGMA DA COMPLEXIDADE • SENTIDOS

\section{Abstract}

From the paradigm of complexity, Organizational Communication is understood as a process of construction and dispute of senses within the scope of organizational relations. Organizational Communication contemplates three stretched and interdependent dimensions: the communicated organization (authorized speech); the communicative organization (authorized speech and other communication processes that are always updated when someone establishes a direct relation with the organization); and the "spoken" organization (communication processes that, although not having direct relations with the organization, make mention to it).

KEYWORDS: ORGANIZATIONAL COMMUNICATION • PARADIGM OF COMPLEXITY • SENSES

\section{Resumen}

Desde el paradigma de la complejidad, se comprende la Comunicación Organizacional como un proceso de construcción y disputa de sentidos en el ámbito de las relaciones organizacionales. Se afirma que contempla tres dimensiones tensas e interdependientes: la organización comunicada (habla oficial); la organización comunicante (habla oficial y demás procesos comunicacionales que se actualizan siempre que alguien establece una relación directa con la organización); y la organización "hablada" (procesos de comunicación que no se producen a partir de relaciones directas con la organización, pero que se refieren a ella).

PALABRAS CLAVE: COMUNICACIÓN ORGANIZACIONAL・PARADIGMA DE LA COMPLEJIDAD • SENTIDOS 
D iversos são os olhares sobre a noção de Comunicação Organizacional e, portanto, as compreensões e as explicações. Os diferentes paradigmas assumidos norteiam e validam tais abordagens, algumas mais férteis, outras nem tanto. Aqui, na perspectiva de atentar para a Comunicação Organizacional em sua diversidade de possibilidades e realizações, o paradigma que orienta a reflexão é o da complexidade, particularmente a partir de Morin (2000a, 2000b, 2002).

Assumir esse paradigma implica reconhecer que a Comunicação Organizacional não se restringe ao âmbito do organizado, à fala autorizada, aos processos formais, à comunicação da e/ou na organização. Exige olhar para além das manifestações organizadas, aparentemente coerentes, de modo a atentar para, entre outras coisas: a dinamicidade organizacional; os processos que mantêm a organização distante do equilíbrio; o estado de incerteza e de permanente desorganização/(re)organização (tensões, disputas, perturbações); a necessária interdependência ecossistêmica (outros sistemas e subsistemas); e os processos recursivos.

Então, na perspectiva dos três princípios básicos da complexidade - conforme Morin, o dialógico ${ }^{1}$, o recursivo ${ }^{2}$ e o hologramático ${ }^{3}-$, redimensiona-se a noção de Comunicação Organizacional ${ }^{4}$ de modo a transpor a ideia de organização comunicada (a fala oficial, planejada) e, também, a de organização comunicante (contempla toda comunicação que se realiza nas diferentes relações que os sujeitos - pessoas/públicos - estabelecem com a organização).

\section{Três dimensões da Comunicação Organizacional}

Diante das características da sociedade contemporânea, tais como a urgência nas decisões (e, portanto, o pouco tempo para investigar e refletir), o desejo de poder (exercer-se sobre a alteridade), o enfraquecimento dos vínculos, a velocidade com que as informações circulam (potência tecnológica), a tendência ao espetáculo, a valorização do imediato e o desejo de fórmulas que permitam a mensuração de tudo - inclusive do intangível -, a ideia de Comunicação Organizacional parece ser reduzida, particularmente no nível

10 princípio dialógico compreende a "associação complexa (complementar, concorrente e antagônica) de instâncias necessárias 'junto' à existência, ao funcionamento e ao desenvolvimento de um fenômeno organizado" (MORIN, 2000a, p. 201); associa/une termos do tipo organização/desorganização, ordem/ desordem, sapiens/demens, mantendo, assim, a dualidade no seio da unidade.

2 De acordo com Morin (2001, p. 108), o princípio recursivo consiste em "processo em que os produtos e os efeitos são ao mesmo tempo causas e produtores daquilo que os produziu" - a sociedade constrói o sujeito que a constrói.

30 princípio hologramático contempla a ideia de que "a parte não somente está no todo; o próprio todo está, de certa maneira, presente na parte que se encontra nele" (MORIN, 2002, p. 101), sendo que parte e todo são ao mesmo tempo mais e menos.

4 Essa discussão foi (re)apresentada em trabalhos anteriores (BALDISSERA, 2004, 2008a, 2008b e 2009. 
das práticas cotidianas, à comunicação planejada. A postura tende a ser a da supervalorização dos processos planejados em detrimento de todos as demais realizações comunicacionais. Especial atenção recebem os processos que, de alguma forma, se traduzem em algo tangível, como os jornais institucionais, as campanhas publicitárias, os eventos, os sites, os materiais informativos para imprensa (e a clipagem) e outros. Ações mensuráveis (tradução em números) são mais valorizadas.

Porém, se é possível quantificar os anúncios, avaliar o aumento nas vendas, verificar os acessos ao site, contabilizar os valores correspondentes à geração de matérias não pagas etc. isso não significa que a comunicação possa ser reduzida a esses processos e, tampouco, afirmar que eles são os únicos responsáveis pelos resultados. Importa observar que assim como existem intenções no polo da produção e proposição também existem intenções nos interlocutores.

De qualquer forma, mais do que discorrer sobre a validade de tais mensurações (e da qualidade dos indicadores que tendem a ser empregados), atenta-se, aqui, para o fato de que tal postura tende a reduzir a Comunicação Organizacional àquilo que é a organização comunicada, isto é, aos processos formais e, até, disciplinadores, da fala autorizada; àquilo que a organização seleciona de sua identidade e, por meio de processos comunicacionais (estratégicos ou não), dá visibilidade objetivando retornos de imagem-conceito ${ }^{5}$, legitimidade, capital simbólico (e reconhecimento, vendas, lucros, votos etc.). Portanto, a ideia de organização comunicada compreende os processos de comunicação autorizada, muitos deles orientados para o auto-elogio.

Em grau mais complexo, pode-se falar da Comunicação Organizacional em seu nível de organização comunicante. Aqui, ultrapassando o âmbito da fala autorizada, atenta-se para todo processo comunicacional que se atualiza quando, de alguma forma e em algum nível, qualquer sujeito (pessoa, público) estabelecer relação com a organização. Além dos processos planejados, também assumem relevo os processos que se realizam na informalidade; inclusive aqueles que irrompem sem que a organização tenha conhecimento. Assim, mesmo que a organização não deseje comunicar, se alguém - alteridade - atribuir sentido a algo e/ ou alguma coisa dela e assumir isso como comunicação, então será comunicação (perspectivas de Eco, 1997; e de Watzlawick; Beavin; Jackson, 1993).

Essa compreensão permite dar relevo aos processos dialógico-recursivos, pois atenta para a possibilidade e fertilidade de ocorrência de relações comunicacionais que escapam ao planejamento (e controle), inclinadas a assumir mais

5 Imagem-conceito consiste em "um constructo simbólico, complexo e sintetizante, de caráter judicativo/ caracterizante e provisório realizada pela alteridade (recepção) mediante permanentes tensões dialógicas, dialéticas e recursivas, intra e entre uma diversidade de elementos-força, tais como as informações e as percepções sobre a entidade (algo/alguém), o repertório individual/social, as competências, a cultura, o imaginário, o paradigma, a psique, a história e o contexto estruturado" (BALDISSERA, 2004, p. 278). 
potência para perturbar a ordem posta (organização, cultura organizacional, organização comunicada) tendendo a forçá-la a movimentos de (re)organização. Da mesma forma, considerando-se que os diferentes sujeitos que se relacionam com a organização são portadores de suas culturas (princípio hologramático) e que no âmbito da comunicação informal a organização tende a ter seu poder flexibilizado, é possível que a alteridade se manifeste com mais força nas transações de sentidos. Isso pode significar, entre outras coisas, novos investimentos em comunicação formal para, por exemplo, neutralizar uma percepção equivocada da alteridade sobre a organização.

Dito isso, ainda é possível redimensionar a noção de Comunicação Organizacional para que contemple outras materializações comunicacionais que dizem respeito às organizações, mas que pouco são pensadas como Comunicação Organizacional. Trata-se dos processos de comunicação informal indiretos; aqueles que se realizam fora do âmbito organizacional e que dizem respeito à organização - algo como a organização falada. Como exemplos, pode-se pensar: nos processos que se atualizam entre colegas de trabalho quando, juntos, participam de um jogo de futebol e discorrem sobre a organização; nas manifestações sobre ela que assumem lugar nas relações familiares; nos processos especulativos; e nas conversas sobre a organização que se realizam entre vizinhos e/ ou nos grupos de pais na reunião da escola. Esses processos, que podem parecer distantes e sem relevância, também são Comunicação Organizacional, ainda que se reconheça a impotência da organização em estabelecer qualquer controle direto sobre eles. Porém, isso não a impede de realizar algum tipo de acompanhamento, até porque, caso desses encontros surjam boatos sobre a organização, à medida que se tornarem visíveis e forem identificados por ela, é possível que exijam algum tipo de investimento em ações e/ ou comunicação formal para neutralizá-los, se for o caso.

\section{Comunicação organizacional: uma compreensão}

Após discorrer sobre essas três importantes dimensões, importa (re)apresentar a compreensão que se assume de Comunicação Organizacional: "processo de construção e disputa de sentidos no âmbito das relações organizacionais" (BALDISSERA, 2008a, 169). Procura-se, assim, dar relevo ao fato de que os diferentes sujeitos em iteração comunicacional são forças em relação (FOUCAULT, 1996), forças essas portadoras de redes simbólicas de seus grupos. Portanto, em diálogo (BAKHTIN, 1999), disputam, (re)constroem os sentidos em circulação nos processos comunicacionais, isto é, além de ser fortemente marcado pela contextura eco-psico-histórico-sociocultural em que se realiza, esse diálogo presentifica sujeitos (identidade/alteridade) tensionados como forças em relação.

Por fim, ressalta-se que toda comunicação que, de alguma forma e em algum grau, disser respeito à organização é considerada Comunicação Organizacional, mesmo que, quando das práticas, seja necessário proceder a algumas 
simplificações no sentido de dar agilidade aos processos. É nessas práticas e, particularmente, no nível da organização comunicada que se estabelecem as fragmentações em Comunicação Mercadológica, Institucional, Interna, Administrativa, dentre outras. No entanto, parece mais fértil pensar a Comunicação Organizacional em sentido complexo, seja para assumir a incerteza como presença, para respeitar e fortalecer a diversidade (possibilitar que se realize/ manifeste), fomentar lugares de criação e inovação, potencializar o diálogo e os fluxos multidirecionais de comunicação, reconhecer as possibilidades de desvios de sentidos e compreender a alteridade como força em disputa de sentidos, dentre outras coisas.

\section{Referências}

BAKHTIN, Mikhail. Marxismo e filosofia da linguagem: problemas fundamentais do método sociológico na ciência da linguagem. 9. ed. São Paulo: Hucitec, 1999.

BALDISSERA, Rudimar. Imagem-conceito: anterior à comunicação, um lugar de significação. Porto Alegre, 2004. Tese (Doutorado em Comunicação Social) - PUC-RS.

. Comunicação organizacional: uma reflexão possível a partir do paradigma da complexidade. In: OLIVEIRA, Ivone de L.; SOARES, Ana Thereza N. (Org.). Interfaces e tendências da comunicação no contexto das organizações. São Caetano do Sul, SP: Difusão, 2008a. p.149-77.

Por uma compreensão da comunicação organizacional. In: SCROFERNEKER, Cleusa M. A. (Org.). 0 diálogo possível: comunicação organizacional e paradigma da complexidade. Porto Alegre: Edipurs, 2008b. p. 31-50.

. A teoria da complexidade e novas perspectivas para os estudos de comunicação organizacional. In: KUNSCH, Margarida M. Krohling (Org.). Comunicação organizacional. Vol. 1. Histórico, fundamentos e processos. São Paulo: Saraiva, 2009. p. $135-164$

ECO, Umberto. Interpretação e superinterpretação. São Paulo: Martins Fontes, 1997.

FOUCAULT, Michel. Microfísica do poder. 12. ed. Rio de Janeiro: Graal, 1996.

MORIN, Edgar. Meus demônios. Rio de Janeiro: Bertrand Brasil, 2000a.

Ciência com consciência. 4. ed. Rio de Janeiro: Bertrand do Brasil, 2000b. Introdução ao pensamento complexo. 3. ed. Lisboa: Instituto Piaget, 2001.

0 método 4. 3. ed. Porto Alegre: Sulina, 2002.

WATZLAWICK, Paul; BEAVIN, Janet H.; JACKSON, Don D. Pragmática da comunicação humana: um estudo dos padrões, patologias e paradoxos da integração. São Paulo: Cultrix, 1993. 